Article

\title{
Fixed Fiber Light Guide System with Concave Outlet Concentrators
}

\author{
Bangdi Zhou, Kaiyan He *, Ziqian Chen * and Shuiku Zhong
}

check for

updates

Citation: Zhou, B.; He, K.; Chen, Z. Zhong, S. Fixed Fiber Light Guide System with Concave Outlet Concentrators. Energies 2022, 15, 982. https://doi.org/10.3390/en15030982

Academic Editor: Jesús Polo

Received: 30 December 2021

Accepted: 25 January 2022

Published: 28 January 2022

Publisher's Note: MDPI stays neutral with regard to jurisdictional claims in published maps and institutional affiliations.

Copyright: (c) 2022 by the authors. Licensee MDPI, Basel, Switzerland. This article is an open access article distributed under the terms and conditions of the Creative Commons Attribution (CC BY) license (https:/ / creativecommons.org/licenses/by/ $4.0 /)$.
School of Physical Science and Technology, Guangxi University, Nanning 530004, China; 1907301114@st.gxu.edu.cn (B.Z.); newzhongshuiku@163.com (S.Z.)

* Correspondence: gredhky@gxu.edu.cn (K.H.); czq8676@163.com (Z.C.)

\begin{abstract}
Because a traditional optical fiber light guiding system includes a tracking device, it also inevitably has a complex structure, high construction and maintenance costs, short life span and low reliability. Although several types have been developed for decades, there are no successful products on the market. The biggest cause of the problem is that all traditional optical fiber light guiding systems must have a tracking device. This paper studies a solar fiber optic guide system without a tracking device, hoping to solve this problem. A fixed fiber light guide system using concave outlet concentrators as its receiving unit is proposed. The structure and working principle of the concave outlet concentrator, the receiving unit and the light guide system are introduced. With optical simulation software and the actual sunlight experimental method, this paper first discusses the conceptual design of the concentrator, then studies the transmission efficiency curve of the receiving unit with different angles of incident light, and finally tests the output illuminance of the whole system in actual sunlight. Field test results show that when the average sunshine intensity is about $800 \mathrm{~W} / \mathrm{m}^{2}$, the system has an output of nearly 300 lux at $0.4 \mathrm{~m}$ in front of the outlet end of the fiber bundle with only $3.11 \times 10^{-2} \mathrm{~m}^{2}$ receiving area. This illumination has been able to meet people's daily lighting requirements. The results of computer simulation and actual sunlight experiments show that this fixed optical fiber light guide system with non-tracing structure is feasible. The absence of a tracking structure means that all moving parts of the system are completely discarded. This greatly improves the working reliability and operation life of the light guide system, and greatly reduces the maintenance and operating costs.
\end{abstract}

Keywords: concentrator; light guide; optical fiber solar system; solar daylighting

\section{Introduction}

With the introduction of low-carbon and green lighting concepts in modern society, the lighting mode of deep interior spaces such as basement through solar lighting has attracted extensive attention [1]. At present, there are two main transmission modes on the market to guide sunlight indoors, namely the light tube scheme and the optical fiber light guide scheme. Since the first set of light tube system products was put into application, light tube technology has been relatively mature after decades of development. Recently, researchers have explored more detailed research on the application of light tubes [2-5]. Another scheme, the optical fiber light guide [6], has advantages such as high illumination intensity, flexible light transmission, small space occupancy and so on. As far as this scheme is concerned, there are multiple alternatives; for example, Takashi Nakamura designed an optical waveguide system for solar power applications in space $[7,8]$. However, there are still no technologically mature products on the market, and the relevant technology is still evolving [9].

At present, the solar concentrators in optical fiber daylighting system are mainly divided into reflective, transmissive and hybrid concentrators. The lighting system using a butterfly solar concentrator $[10,11]$ or trough concentrator [12-14] as its reflective concentrator is a research hotspot. A transmission concentrator mainly includes ordinary convergent 
lenses and Fresnel lenses. Recently, Lei Li et al. proposed a large Fresnel lens optical fiber daylighting system, and its optical efficiency can reach $11-13 \%$ [15]. Vu, N.H. et al proposed an optimized Fresnel lens fiber daylighting system (m-ofds). The system simulation results show that its maximum optical efficiency is $71 \%$. The simulation results also show that the distance that sunlight can be transmitted to the lighting destination is $30 \mathrm{~m}$ [16]. For a system with hybrid concentrators, Obianuju et al. used a new two-stage reflective non imaging dish concentrator for collection [17]. Dawei et al. reported on a flexible light guide, which consists of 19 optical fibers and compound parabolic concentrators, and its efficiency can be over $60 \%[18,19]$. In addition, many hybrid optical fiber daylighting and photovoltaic solar lighting systems were also proposed recently [20-22]. However, all these light guiding systems mentioned above require tracking systems with mechanical moving parts and an external power supply. That is a big problem for all traditional optical fiber light guiding systems. The inclusion of tracking devices inevitably results in a complex structure, high construction and maintenance costs, a short life span and low reliability, which is not conducive to market promotion. Efficiency and cost are two important issues in energy application technologies. In general, in solar energy applications, systems with tracking devices are more efficient, while systems without tracking devices are less efficient; the same is true terms of cost. From the history of technology development, the application of tracking devices in large and medium-sized solar systems is commercially reasonable and successful, but the application of tracking devices in small systems, especially small civilian systems, is commercially unsuccessful. Given the endless supply of solar energy, home users are more concerned about maintenance and operating costs, operating reliability and service life. It is easy to understand this issue when you consider the most successful solar product, the solar water heater. Solar water heaters for home use have no tracking device, low cost, long life and are almost maintenance-free. Based on this consideration, in the field of solar light guiding, we also hope to develop a solar light guiding system without a tracking device.

In 2007, a specially designed composite parabolic concentrator was introduced [23]. Subsequently, more in-depth studies were carried out [24,25]. In 2019, based on this concentrator, a fixed optical fiber daylighting system was proposed [26]. For a traditional optical fiber guide system, its shortcomings of high cost, complex structure, low reliability and short life are largely due to the tracking device. However, this fixed system described above completely abandons the tracking device, which would greatly improve the shortcomings of the traditional optical fiber guide system. In this paper, a new structure will be designed to make the fixed fiber light guide system simpler, more reliable and more efficient in higher light energy coupling.

\section{The Structure and Working Principle}

In the literature published in 2019 [26], a non-tracking light guide system based on the principle of total internal reflection was proposed. The receiving unit of that system that undertakes the solar receiving task is shown in Figure 1a. One of the very important components in this figure is a concentrator with a convex outlet. After further research and analysis on this structure, it was found that this structure still has room for change. Therefore, we propose a new type of receiving unit, as shown in Figure 1b. It can be seen that at least two different designs have been done. Firstly, the optical coupler has been omitted. The benefits are reducing specular reflection and becoming a simpler structure. Secondly, under the same conditions as other geometric parameters of the concentrator, smaller optical fibers can be used to reduce the cost.

The concave outlet concentrator is made of solid block transparent material, as shown in the physical photo in Figure 2a. It realizes light propagation based on the principle of total internal reflection rather than specular reflection. The concave design of the outlet of the concentrator is based on the following reasons. Taking a look at the ray tracing simulation when the bottom end of the outlet is simply made into a plane, as shown in Figure 3a, it can be seen that after the converged exit beam is emitted from the solid 
concentrator into the air, its convergence angle is large, which is obviously not conducive to the coupling with the optical fiber.

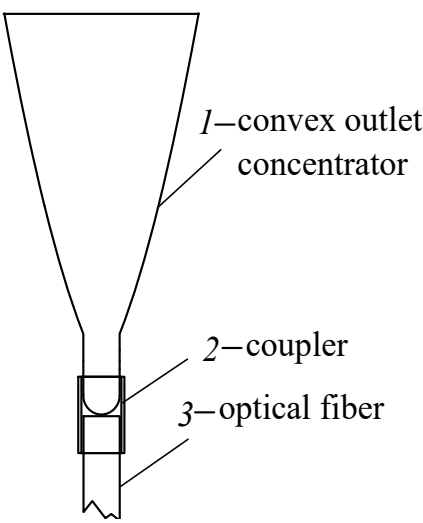

(a)

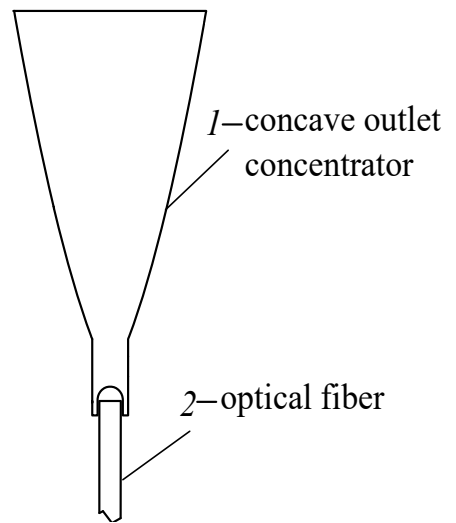

(b)

Figure 1. (a) Receiving unit with a convex outlet concentrator. (b) Receiving unit with a concave outlet concentrator.

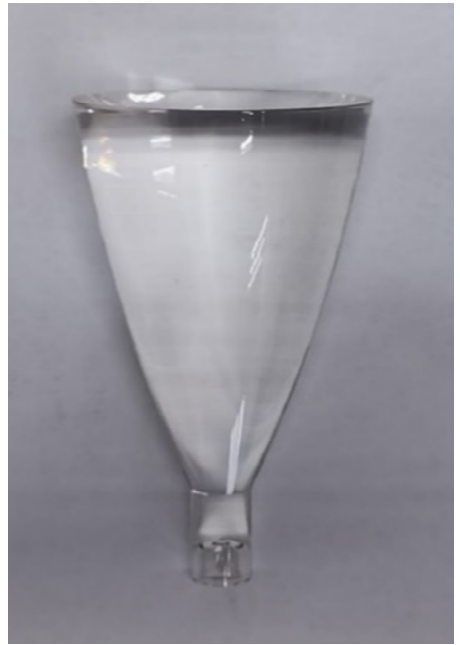

(a)

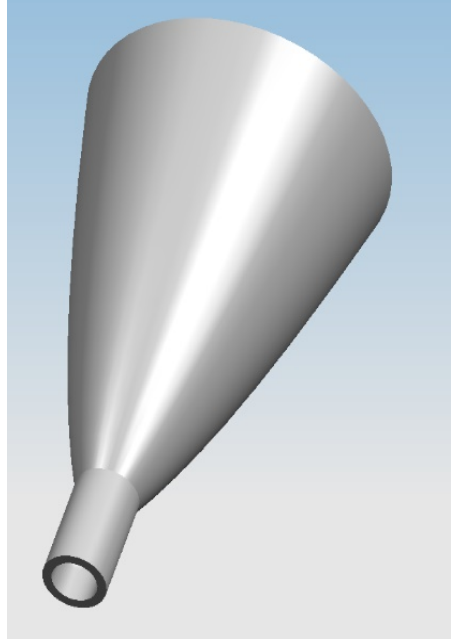

(b)

Figure 2. (a) Physical photo of the concave outlet concentrator. (b) A computer model of the concave outlet concentrator.

Therefore, we changed the flat bottom into a concave spherical structure, which is an arc seen from the outer contour of the shaft section. The outlet end of the concentrator is actually a concave lens. Ray tracing simulation on it is shown in Figure 3b. This shows that the convergence angle of exit beam is smaller than that in Figure 3a, which is good for light transmitting to fiber.

The preliminary design of the concentrator is discussed below. According to the discussion in the literature [24], the geometric structure of the full-size concentrator can be determined as long as the outlet width $l$ and the characteristic parameter $k$ are given ( $k$ is defined in the Appendix A). Let $l=0.014 \mathrm{~m}$ (AB in the Figure 4 ) according to the available experimental conditions. In order to obtain the optimal $k$ value, we do the following processing: According to the reasonable range of $k$ value discussed in the literature [24], 11 different values of $k$ are determined, and 11 corresponding computer models of the concentrator with slightly different sizes are established. Then, 11 models with the same $l$ value and the same inlet width are respectively imported into the optical software (LightTools) for ray tracing simulation, and their light transmission efficiency was 
measured. The wavelength of incident light is set to $550 \mathrm{~nm}$, the number of rays to 15,000 , and the transmittance of the material to $100 \%$. The results are shown in Figure 4.

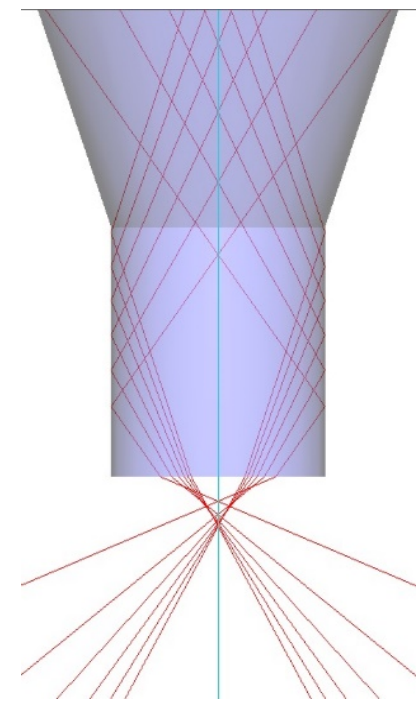

(a)

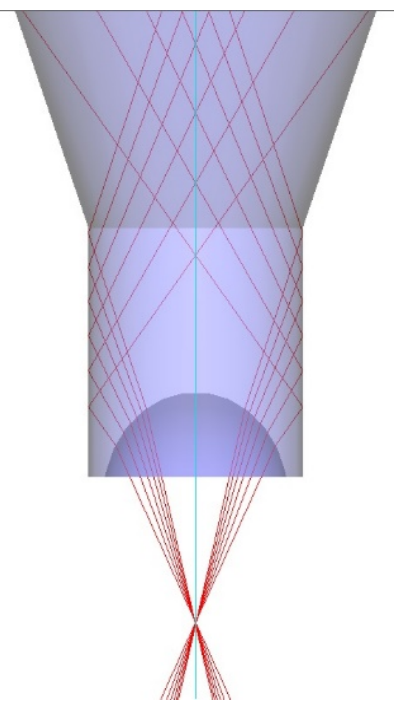

(b)

Figure 3. (a) Ray tracing simulation for a flat outlet concentrator. (b) Ray tracing simulation for a concave outlet concentrator.

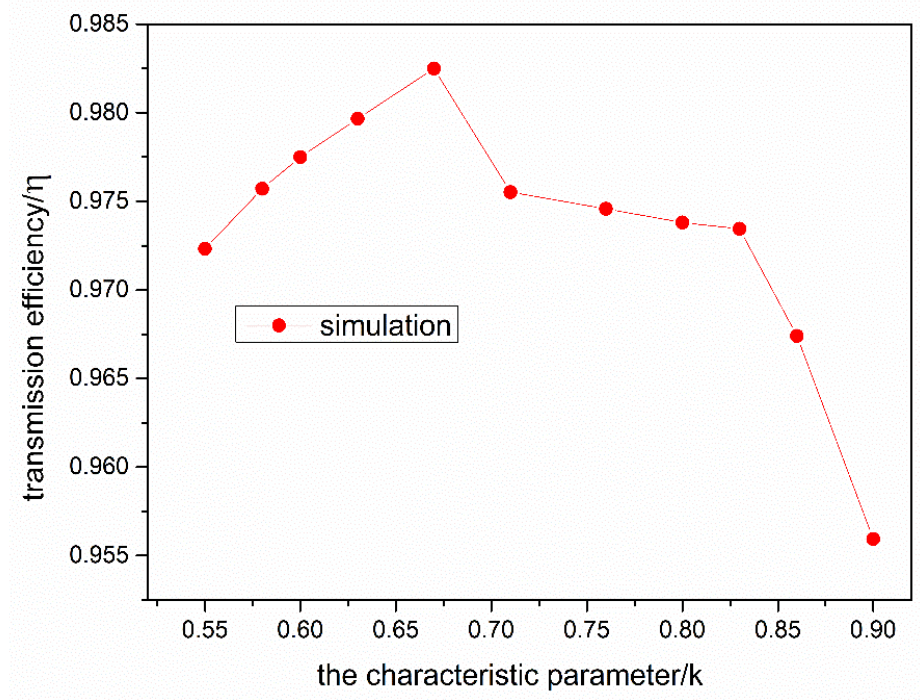

Figure 4. Variation curve of light transmission efficiency with characteristic parameters.

The results correspond to the condition of normal incidence of light and connect with the optical fiber. The light transmission efficiency here is defined according to the following formula [26].

$$
\eta=\frac{\text { number of the effective emergent rays }}{\text { number of the effective incident rays }}
$$

The effective emergent rays refer to the light rays emitted from the fiber terminal, which is measured by a detection board (a round red board) very close to the end of the optical fiber, as shown in Figure 5. Effective incident rays refer to the light rays entering into the inlet end (receiving surface, or DC in the Figure 6) of the concentrator. It is measured with the help of a detector board at the entrance (a square red board at the entrance of the concentrator in Figure 5). The length and width of this board are larger than the entrance of the concentrator and larger than the cross section of the incident beam. A hole in the 
middle of the square board has the same area as the entryway of the concentrator. Under the isoplanar condition, the board just covers the entryway of the concentrator. A square column is selected for the incident beam. As long as the light rays do not overflow the square detector board, the effective incident ray number is equal to the ray number of the incident beam minus the ray number on the detection board. Figure 4 shows that there is a maximum value when the $\mathrm{k}$ value is between $0.65-0.68$. After comprehensive consideration of various factors, the value of $k$ is finally determined to be 0.667 . Thus, the values of the two parameters, $\mathrm{k}$ and $l$, that determine the concentrator shape are 0.667 and $0.014 \mathrm{~m}$, respectively, which are the geometric parameters of the concentrators used in the experiment.

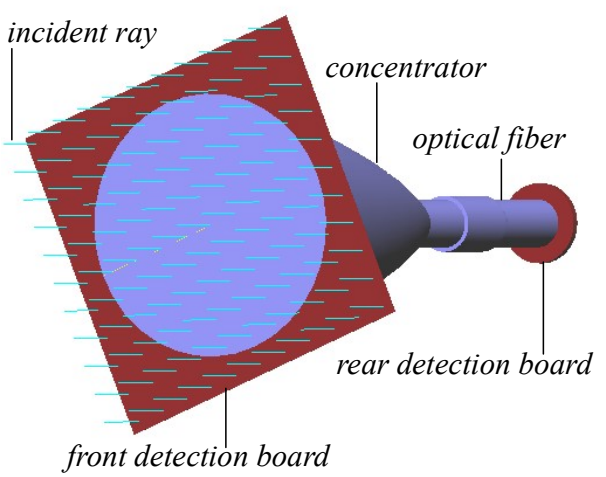

Figure 5. Schematic diagram of ray number detection.

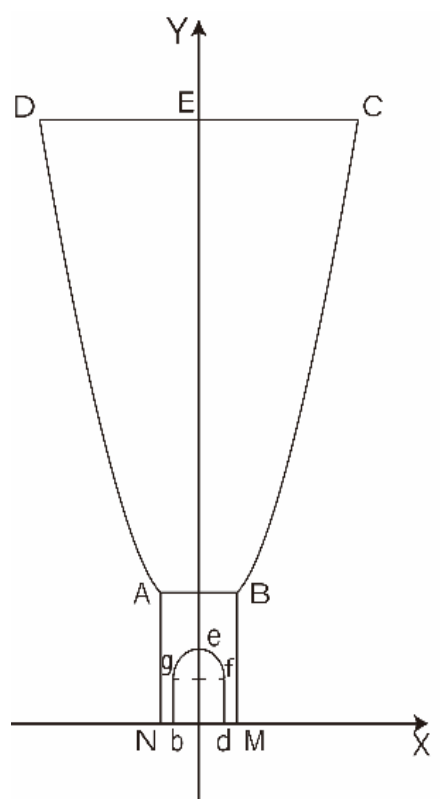

Figure 6. Axial section structure drawing of concentrator.

The detailed axial section geometry of the concentrator is shown in Figure 6. The parabolic $\mathrm{CB}$ equation is:

$$
y=\frac{1}{18.2}(x+l)^{2}
$$

where $l$ is the length of the line AB. It is the outlet width of the concentrator. The lengths of the lines $\mathrm{DC}, \mathrm{AB}$ and $\mathrm{dM}$ are $66.34 \mathrm{~mm}, 14 \mathrm{~mm}$ and $2 \mathrm{~mm}$, respectively (the experimental model is not a full-scale model. Its height has been truncated by $20 \%$ ). The segment ef is a quarter arc with a radius of $5 \mathrm{~mm}$. When the curve composed of the six segments EC, $\mathrm{CB}, \mathrm{BM}, \mathrm{Md}$, $\mathrm{df}$ and fe rotates the $\mathrm{Y}$ axis, the concentrator would be obtained, as shown in 
Figure $2 \mathrm{~b}$. The $\mathrm{Y}$ axis is its symmetry axis. The calculations of geometric parameters of the front part that is above the focal point of the concentrator are in Appendix A.

\section{Results and Discussion}

This section is divided by subheadings. It will provide a concise and precise description of the experimental results, their interpretation, as well as the experimental conclusions that can be drawn. It will briefly and accurately describe the experimental process, methods and results, and analyze the results.

\subsection{Research on the Transmission Efficiency of the Receiving Unit}

To better explore the receiving performance of the concentrator, it was necessary to measure the change of its transmission efficiency under the irradiation of sunlight with different incident deflection angles. The measurement includes computer ray simulation and experiments under actual sunlight conditions. One point to make here is that the concave outlet concentrator is coupled with the transmission optical fiber to form a socalled receiving unit, as shown in Figure 5. The measurement results are shown in Figure 7. Here, we focused on the attenuation characteristic, that is, the shape of the curve, not the specific value of the transmission efficiency. Therefore, the experimental curve was normalized. The transmission efficiency was set to 1 when the incident angle was 0 degrees. The red line in the figure is the results from the computer ray tracing simulation, which uses ray number as an energy unit. The conditions of the simulation are as follows: The transmittance of the concentrator is $100 \%$ without considering the absorption loss of the material, and the incident light is monochromatic light with a wavelength of $550 \mathrm{~nm}$. The black line is the result from the actual solar experiment, which uses solar irradiance as the energy unit. In the figure, the angle $\Phi$ is the deviation angle from normal incidence.

It can be seen from Figure 7 that the shape of the two curves is similar, and that with the increase in the incidence angle the transmission efficiency gradually decreases. When the incident parallel light rays gradually deviate from the normal, making the propagation process of the light more complex, more light rays cannot be fully reflected into effective output light rays; they go out of the side, as shown in Figure 8. Therefore, the output will decay gradually as the declivity angle of the incident light rays increases. Of course, loss also includes material absorption, which has to do with the wavelength of light, but this loss is hardly reflected in the attenuation curve, because it hardly has much to do with the deflection angle. In other words, different wavelengths will get different efficiencies, but do not affect the shape of the efficiency curve in Figure 7.

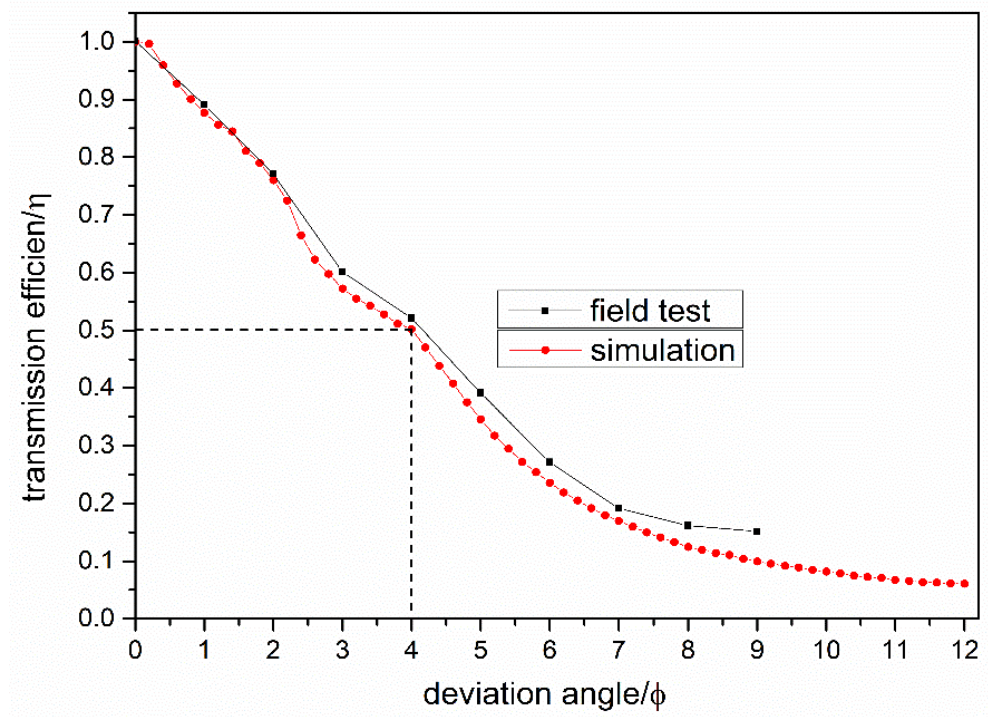

Figure 7. Variation curve of transmission efficiency of a receiving unit with a deflection angle. 


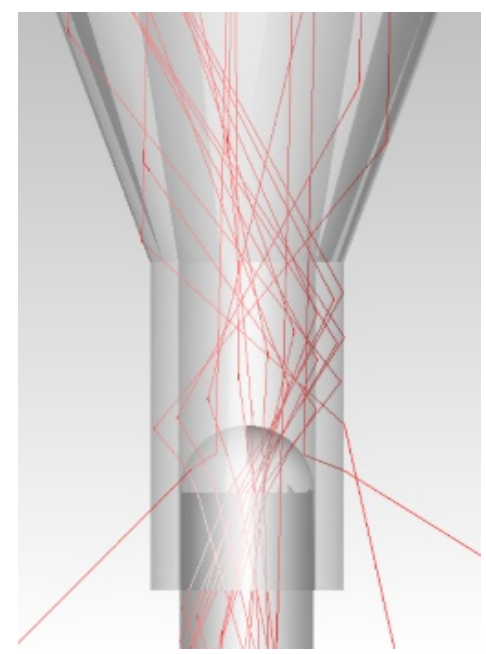

Figure 8. Ray tracing simulation with a small deflection angle.

Another point that needs to be noted is that when the deflection angle become large (more than $8^{\circ}$ in figure), the simulation curve still attenuates relatively rapidly, but the experimental curve attenuates relatively slowly. The reason is that sunlight contains both direct light and scattered light. As the deviation angle increases, the loss of direct light gradually increases, and it counts for less and less proportion. However, the scattered light almost stays the same, just taking up more and more proportion. Therefore, the field experimental curve decays slowly at a large angle deflection. However, the incident light corresponding to the computer simulation curve includes only direct light, no scattered light. Therefore, it is still decaying at a relatively fast rate.

However, we should note that the decay is not sudden, but gradual. It can be seen from Figure 7 that when the deflection angle is $4^{\circ}$, the transmission efficiency of the receiving unit is still close to 0.5 . That is half of the max transmission efficiency. The value of $4^{\circ}$ here is called the full width at half maximum (short for FWHM) of this receiving unit.

Theoretically, if the defects of the device manufacturing and system assembly are not considered, the influence of the deviation of sunlight on the transmission efficiency is axisymmetric in spatial orientation. Therefore, for a fixed receiving unit, the complete light transmission efficiency curve should be as shown in Figure 9. For any receiving unit, the corresponding light transmission efficiency curve has a full width at half maximum, that is, $\Phi_{\mathrm{m}}$ in the figure. Specifically, for the model we have established, the FWHM is $\Phi_{\mathrm{m}}=4^{\circ}$. This transfer efficiency curve is a very important curve that we rely on to build a fixed optical fiber guide system.

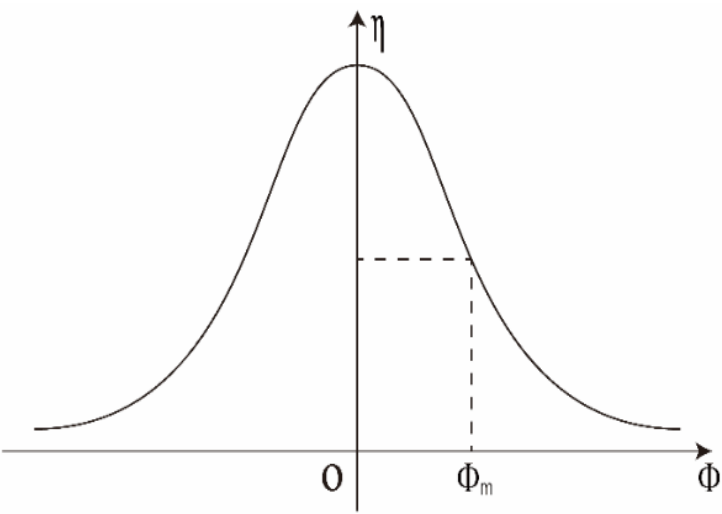

Figure 9. The complete ray transfer efficiency curve of the receiving unit. 


\subsection{Fixed Fiber Light Guide System}

As we can see from the discussion in the previous section, only when the sun moves to the normal incidence position of the receiving unit can the maximum receiving effect be obtained by simply relying on a fixed receiving unit to receive sunlight. Once it deviates from the normal incidence position, receiving efficiency will decrease. The greater the deviation angle, the less the efficiency. However, the feature of the transmission efficiency curve of the receiving unit gives us an inspiration. If we stagger multiple receiving units at certain angles intervals (for example, $2 \Phi_{\mathrm{m}}$ ) on an arc corresponding to the motion of the sun, a fixed light guide system will be gained, as shown in Figure 10.

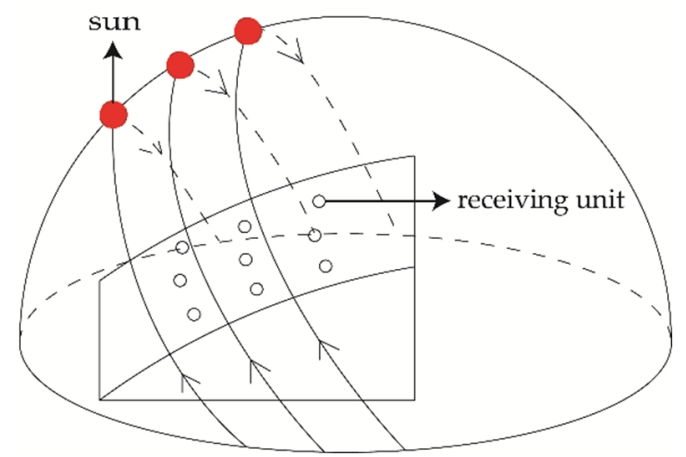

Figure 10. The layout of the receiving unit.

By this arrangement, the resulting fixed light guide system will have a light transmission efficiency curve, which is the staggering superposition of the transmission efficiency curves of nine receiving units, as the red line shows in Figure 11. Within a certain receiving angle range (determined by the number of receiving units), the efficiency curve will be an approximate horizontal line, which is not different from the light guide system with a solar tracking device. It can be seen from Figure 11 that the shape of the curve in Figure 9 is very important. The curve with a large $\Phi_{\mathrm{m}}$ is what we want to get. With a larger $\Phi_{\mathrm{m}}$, the design goal can be achieved with fewer receiving units at the same receiving angle. According to the available experimental conditions, we can get a system including nine receiving units, as seen in Figure 12. The angular interval between two receiving units is equal to $2 \Phi_{\mathrm{m}}=8^{\circ}$. Of the range between $-32^{\circ}$ to $32^{\circ}$, the light transmission efficiency decreases rapidly. Based on the same idea, similar problems coming from the seasonal change can be solved by a multi-row arrangement in the direction of the sun's altitude angle, as shown in Figures 10 and 12.

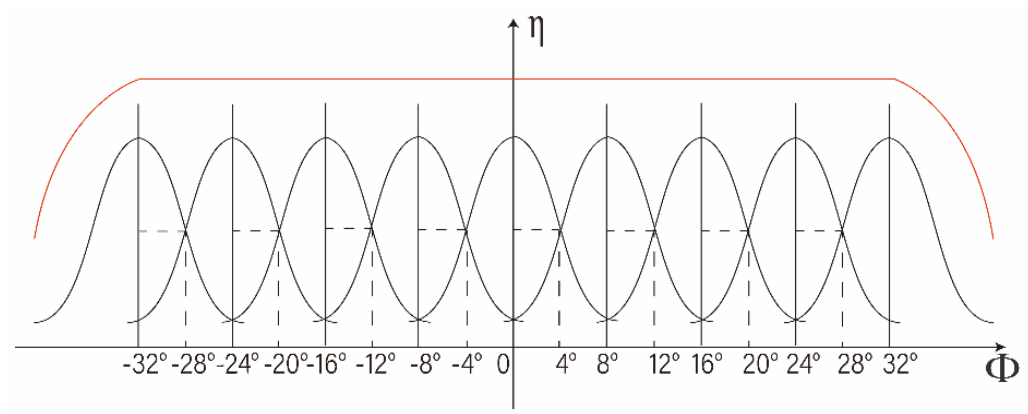

Figure 11. Light transmission efficiency curve of a fixed light guide system. 


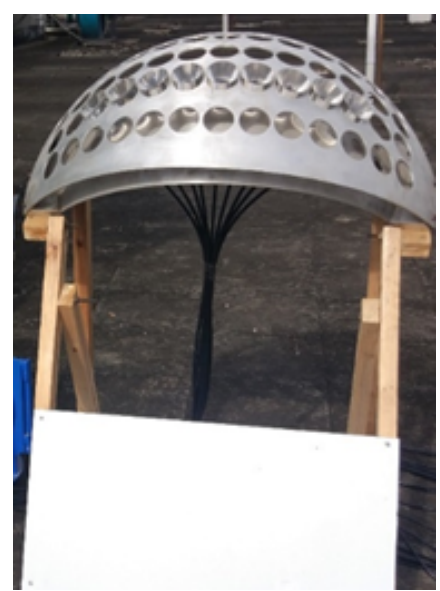

Figure 12. Fixed light guide system.

\subsection{Test on the Fixed Fiber Light Guide System}

The test device is shown in Figure 12. The fiber is a plastic optical fiber with a length of $3 \mathrm{~m}$ and a diameter of $0.005 \mathrm{~m}$. The ends of nine optical fibers are bundled into a square column shape, as shown in Figure 13, and then are inserted into a small darkroom $\left(1.2 \times 1.2 \times 1.8 \mathrm{~m}^{3}\right)$, that is located inside a room (not in the field of view in Figure 12). The measurement point of illuminance is located $0.4 \mathrm{~m}$ in front of the end of the fiber bundle.

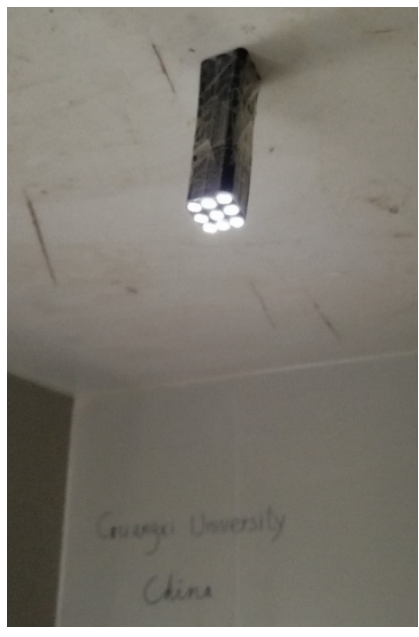

(a)

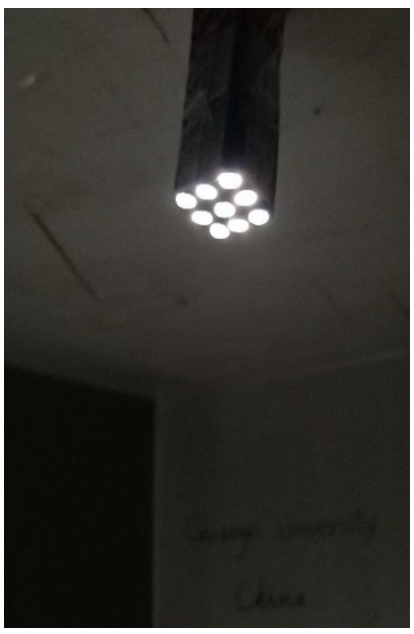

(b)

Figure 13. Photo of the end of the fiber bundle (a) with auxiliary light; (b) without auxiliary light.

The latitude of the experimental site is $23^{\circ}$. When testing, the center line of the light guide system directs to the solar noon position of the sun. Because the sun moves $1^{\circ}$ every $4 \mathrm{~min}$, the range of effective output illuminance received by the fixed light guide system is $64^{\circ}$, which is more than $4 \mathrm{~h}$ of sunshine, that is, $2 \mathrm{~h}$ before noon and $2 \mathrm{~h}$ after noon. The measured data are shown in Figures 14 and 15. The red curve is the irradiance of incident sunlight and the purple curve is the output illuminance. 


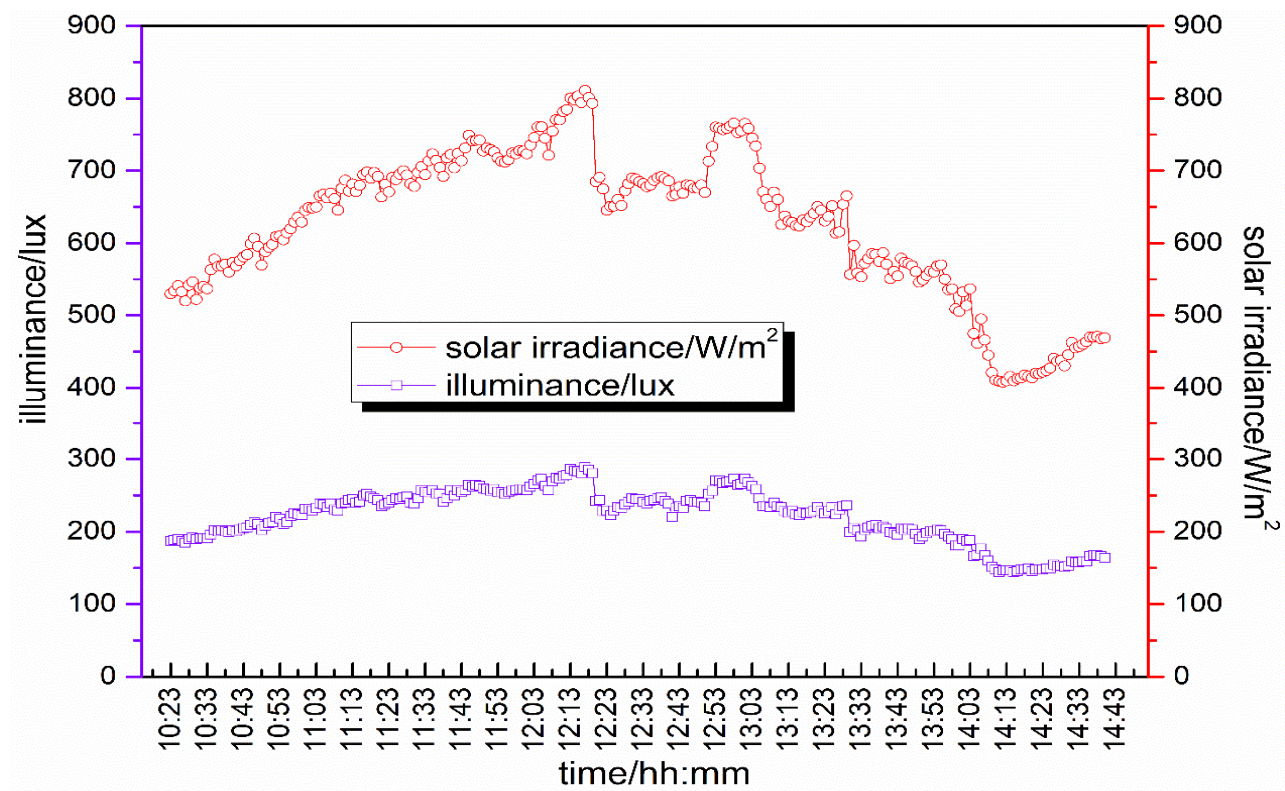

Figure 14. A diagram of the system's output illuminance compared to solar radiation intensity (medium intensity).

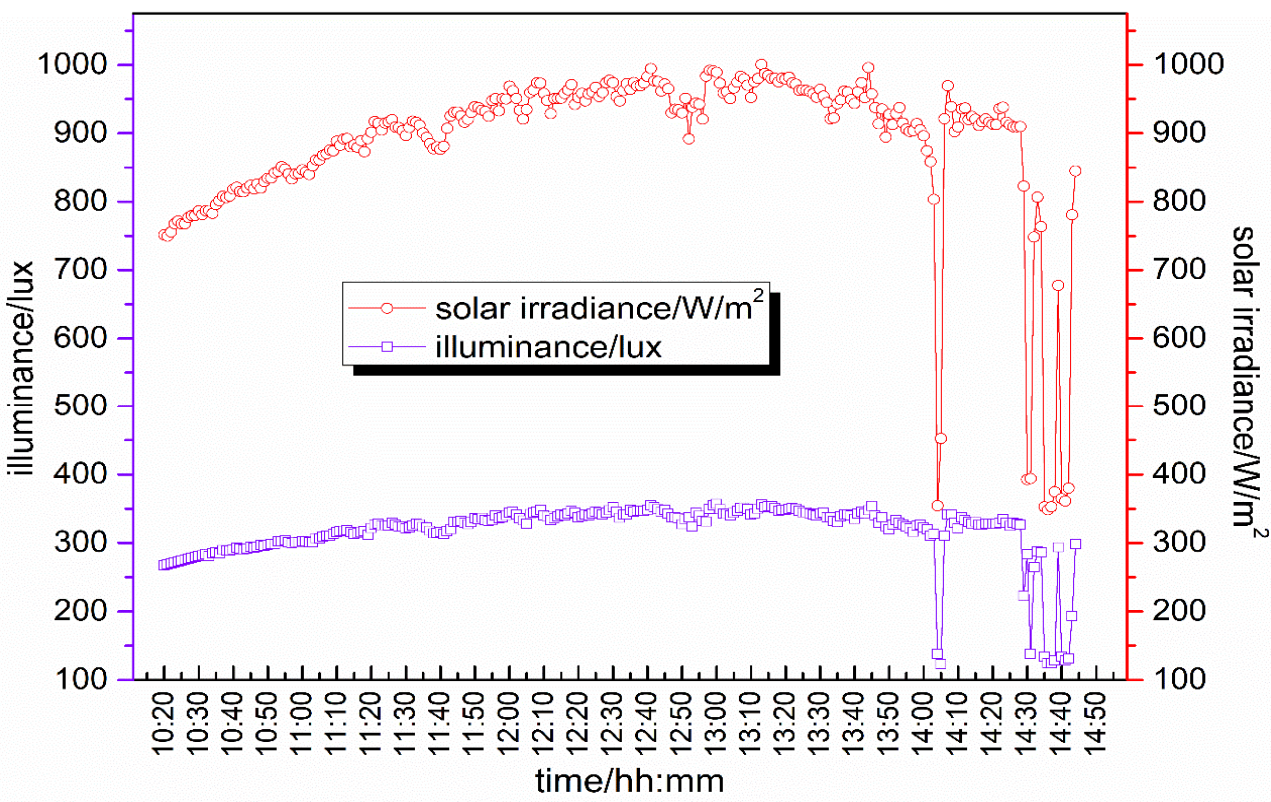

Figure 15. A diagram of the system's output illuminance compared to solar radiation intensity (high intensity).

We can clearly see that the whole output illuminance is almost consistent with the change trend of sunlight irradiance. Without regard to receiving efficiency, the receiving characteristics of this system in receiving sunlight for illumination are the same as the optical guide system with a tracking device. It should be noted that because solar irradiance and illuminance at the end of optical fibers are measured using different instruments that do not have a common time scale system (that is, the two data records are not strictly the same point on the time axis), the change trend of the two curves could not be absolute consistent. The entrance area (solar receiving area) of the nine receiving units is $3.11 \times 10^{-2} \mathrm{~m}^{2}$. In the figure, we can also see that when the average intensity of sunlight is about $600 \mathrm{~W} / \mathrm{m}^{2}$, the output illuminance of the whole system can reach about 200 lux, and when the average intensity of sunlight is about $800 \mathrm{~W} / \mathrm{m}^{2}$, the output illuminance of the whole system can reach about 300 lux. This illuminance intensity can meet the lighting needs of daily rooms. 
From a system architecture perspective, we can improve efficiency and output in the following ways. One way is to shorten the angular interval between the two receiving units. Thus, from Figure 11, we can see that the efficiency curve (red line) will rise. However, it should be noted that if the interval between receiving units remains unchanged, simply increasing the number of receiving units in the same line will not make the efficiency curve rise, but only increase the lighting time. The second way is to increase the number of rows of the receiving unit. The third way is to increase the width $l$ of the concentrator outlet (AB in Figure 6), which also increases the width of its entrance (CD in Figure 6). Therefore, more receiving area will be obtained at the entryway of the concentrator. This method can increase the output. Of course, further optimization of the structure and selection of materials with low absorption loss are also good ways to improve the output.

\title{
4. Conclusions
}

A concave exit concentrator and a related fixed light guide system were proposed, and the performance of the concentrator and the whole system were studied and discussed. Due to the ingenious design, the receiving unit composed of this concentrator with a concave exit structure makes the light more favorable for coupling with the fiber. Thus, the receiving unit can dispense with the couplers and can tolerate smaller diameter optical fibers, greatly simplifying the structure of the receiving unit. The fixed light guide system is composed of multiple rows and columns of receiving units, which is similar to a sunflower. Computer ray tracing simulation and field sunlight experiments show the output of the system at different times (within the range of the available receiving time) of each day of the year without a tracking device. The results of the field experimental test show that the system composed of only one row receiving unit with only $3.11 \times 10^{-2} \mathrm{~m}^{2}$ receiving area had nearly 300 lux output at $0.4 \mathrm{~m}$ in front of the outlet end of the fiber bundle under solar irradiance of about $800 \mathrm{~W} / \mathrm{m}^{2}$, and $200 \mathrm{lux}$ at $600 \mathrm{~W} / \mathrm{m}^{2}$. Such illumination can meet the lighting requirements of general rooms, indicating that the design scheme is feasible. This fixed light guiding system that we developed does not have any moving parts. The inevitable benefits are long life and high reliability. Another advantage is that the structure is very simple. Its main composition is the repeated stacking of the simple components shown in Figure 1b. The main material is glass (not counting optical fiber, because optical fiber is also needed for traditional optical guide systems), and the cost is no higher than that of systems with tracking devices. This new system would provide a new feasible scheme for the commercialization of civilian optical fiber guide products.

Author Contributions: Conceptualization, K.H. and B.Z.; methodology, software and validation, K.H., B.Z., Z.C. and S.Z.; formal analysis, investigation and resources, B.Z.; writing-original draft preparation, B.Z. and Z.C.; writing-review and editing, K.H.; visualization, K.H.; supervision, K.H. All authors have read and agreed to the published version of the manuscript.

Funding: National Natural Science Foundation of China, grant number 51868002.

Data Availability Statement: The data that support the study's findings, such as numerical simulation, model or code generated or used during the study, are available upon request from the journal and the corresponding author.

Acknowledgments: This work is supported by the National Natural Science Foundation of China under grant number 51868002.

Conflicts of Interest: The corresponding author declares that there is no conflict of interest on behalf of all authors.

\author{
Abbreviations \\ $\eta \quad$ transmission efficiency \\ $\mathrm{k} \quad$ eigen parameter of the concentrator \\ $\Phi$ deviation angle \\ FWHM full width at half maximum
}




\section{Appendix A}

Appendix A.1. The Formation of Concentrator and the Calculation Formula of Geometric Parameters above the Focal Point

As shown in Figure A1, the two paraboloids with upward openings, $F_{1}$ and $F_{2}$, are respectively their focal points. Their symmetry axes are parallel to each other, and their equations are, respectively:

$$
\begin{aligned}
& y=\frac{1}{2 p}(x+l)^{2},(p>0) \\
& y=\frac{1}{2 p}(x-l)^{2},(p>0)
\end{aligned}
$$

Coordinates of focus:

$$
\begin{gathered}
x_{F_{1}}=-x_{F_{2}}=-\frac{l}{2} \\
y_{F_{1}}=y_{F_{2}}=\frac{p}{2}
\end{gathered}
$$

where $p$ is the focal parameter of the parabola and $l$ is the horizontal distance between the focal point $F_{1}\left(F_{2}\right)$ and the y-axis, which is also the width of the concentrator outlet $\mathrm{AB}$. Figure A2 is the $3 \mathrm{D}$ and 2D structure diagram of concentrator. Line $\mathrm{Ab}$ is parallel to the $X$-axis. Segment AB must satisfy both conditions: (i) It must be positioned above the focus $F_{1}$ or $F_{2}$ and (ii) its length is exactly the half of the distance.

Between the focal points of the two paraboloids, that is:

$$
|A B|=\frac{\left|F_{1} F_{2}\right|}{2}=l\left(\text { or }|E O|=|O G|=\frac{l}{2}\right)
$$

Lines $\mathrm{AE}$ and $\mathrm{BG}$ are perpendicular to the axis, respectively. Take the parabolic segment $A D$ and $B C$, as well as the straight segment $A E$ and $B G$, rotating around the axis of symmetry; then a 3D concentrator is obtained, as shown in Figure A2a. If it is translated vertically to the plane $x o y$, a trough shaped combined paraboloid concentrator is obtained, as shown in Figure A2b. The working principle of this concentrator, namely the operating principle of optical path, is shown in Figure A3. Incident light is parallel to the symmetry axis (that is, the y-axis). The light rays reflected from the parabolic segment CB should converge at $F_{1}$, but actually converge at point $F$ due to the action of the reflecting mirror AE. The above condition (i) is to ensure that point $F$ is located below the lower opening $A B$ of the parabolic part of the concentrator. Point $F$ is the image of the point $F_{1}$ with respect to the plane mirror $\mathrm{AE}$, which happens to be on the symmetry axis of the concentrator. Similarly, the light rays reflected by the parabolic segment AD, then by the reflection of BG, will also converge to the point $F$. Therefore, point $F$ is the focus of the concentrator.

It can be seen from Figure A3 that ray 2 is already the outermost edge of the ray. The rays to the right of ray 2 will go to DA, instead of propagating down after being reflected by $\mathrm{CB}$. Therefore, the concentrator has an effective minimal width of inlet DC. Tracing ray 2 down, we can see that AE (or BG) also has an effective minimal length. 


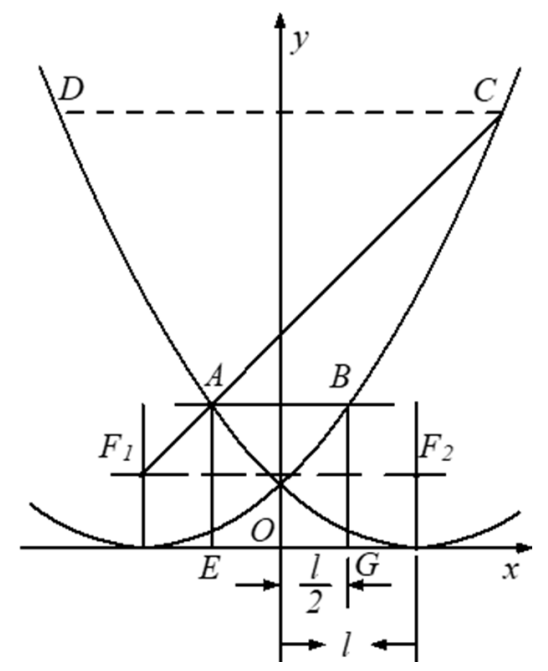

Figure A1. Schematic diagram of the concentrator.

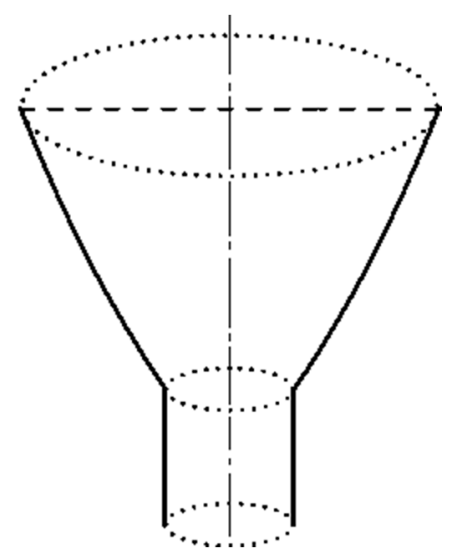

(a)

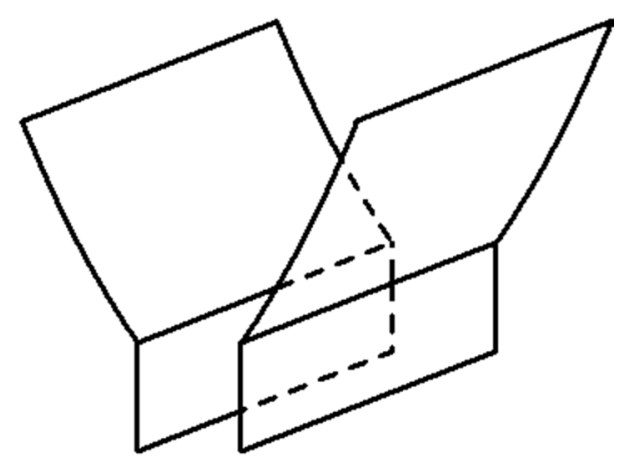

(b)

Figure A2. (a) 3D structure diagram of concentrator; (b) 2D structure diagram of concentrator.

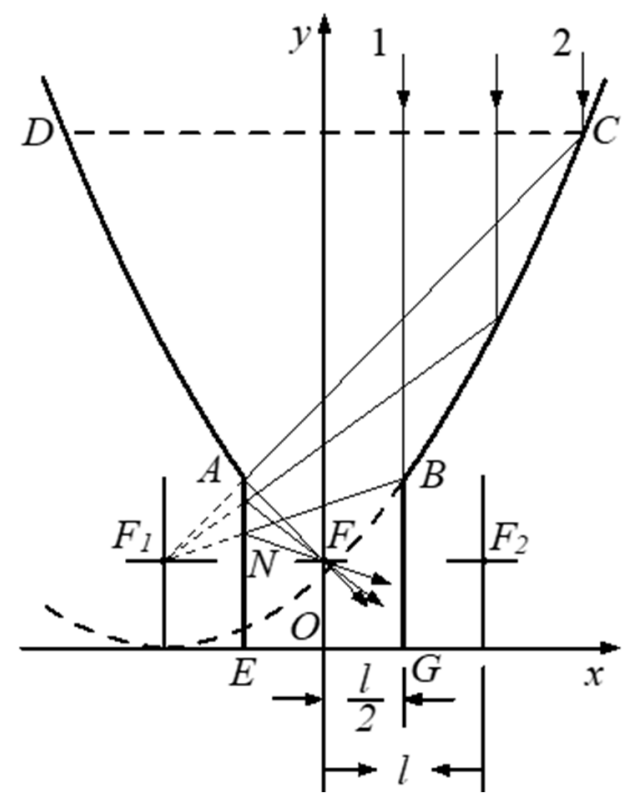

Figure A3. Diagram of light transmission in concentrator. 
Appendix A.2. Determination of Main Geometric Parameters of Concentrator

According to the above two conditions that line segment $A B$ must satisfy, and Equations (A1)-(A4), the following equations will be obtained [24]:

The Minimum Length of the Mirror AN

$$
h=y_{A}-y_{N}=\frac{3 l^{2}}{4 p}-\frac{p}{3}
$$

The Effective Diameter of Entrance Aperture

$$
\Phi=D C=2 x_{C}=2 l\left(\frac{5}{4}-\frac{p^{2}}{l^{2}}+\sqrt{\left(\frac{9}{4}-\frac{p^{2}}{l^{2}}\right)^{2}+\frac{p^{2}}{l^{2}}}\right)
$$

Diameter Ratio of Inlet to Outlet

$$
\beta=\frac{\Phi}{l}=\frac{2 x_{C}}{2 x_{B}}=2\left(\frac{5}{4}-\frac{p^{2}}{l^{2}}+\sqrt{\left(\frac{9}{4}-\frac{p^{2}}{l^{2}}\right)^{2}+\frac{p^{2}}{l^{2}}}\right)
$$

The Ratio of Width to Height for the Tapered Part

$$
\begin{gathered}
H=y_{C}-y_{B}=\frac{p}{2 \frac{p^{2}}{l^{2}}}\left(\left(\frac{9}{4}-\frac{p^{2}}{l^{2}}+\sqrt{\left(\frac{9}{4}-\frac{p^{2}}{l^{2}}\right)^{2}+\frac{p^{2}}{l^{2}}}\right)^{2}-\frac{9}{4}\right) \\
\alpha=\frac{\Phi}{H}=\frac{4 \frac{p}{l}\left(\frac{5}{4}-\frac{p^{2}}{l^{2}}+\sqrt{\left.\left(\frac{9}{4}-\frac{p^{2}}{l^{2}}\right)^{2}+\frac{p^{2}}{l^{2}}\right)}\right.}{\left(\frac{9}{4}-\frac{p^{2}}{l^{2}}+\sqrt{\left(\frac{9}{4}-\frac{p^{2}}{l^{2}}\right)^{2}+\frac{p^{2}}{l^{2}}}\right)^{2}-\frac{9}{4}}
\end{gathered}
$$

The Half Cone Angle of the Outgoing Beam.

$$
\tan \theta=\frac{\frac{A B}{2}}{N E-F O}=\frac{\frac{A B}{2}}{\left(y_{A}-A N\right)-F O}=\frac{\frac{p}{l}}{\frac{3}{4}-\frac{p^{2}}{3 l^{2}}}
$$

The Characteristic Parameter $k$ of the Concentrator.

It can be seen from the above results that the ratio $\frac{p}{l}$ is the only parameter that affects $\alpha \beta \theta$. It is an important parameter that affects the geometric parameters of concentrator and outgoing beam. It is denoted by $k$, that is:

$$
k=\frac{p}{l}
$$

where $k$ is called a characteristic parameter.

According to the above condition (i), we can get:

$$
0<\frac{p}{l}<\frac{3}{2}
$$

and

$$
0<k<\frac{3}{2}
$$


Then, Equations (A8), (A10) and (A11) become as follows. Their corresponding curves are shown in the Figures A4 and A5:

$$
\begin{gathered}
\beta=2\left(\frac{5}{4}-k^{2}+\sqrt{\left(\frac{9}{4}-k^{2}\right)^{2}+k^{2}}\right) \\
\alpha=\frac{4 k\left(\frac{5}{4} k^{2}+\sqrt{\left(\frac{9}{4}-k^{2}\right)^{2}+k^{2}}\right)}{\left(\frac{9}{4}-k^{2}+\sqrt{\left.\left(\frac{9}{4}-k^{2}\right)^{2}+k^{2}\right)^{2}-\frac{9}{4}}\right.} \\
\tan \theta=\frac{k}{\frac{3}{4}-\frac{k^{2}}{3}}
\end{gathered}
$$

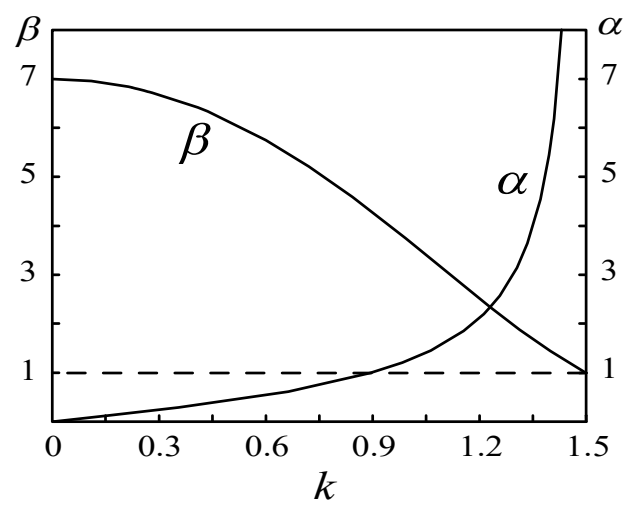

Figure A4. The curves of $\alpha$ and $\beta$ with respect to $k$.

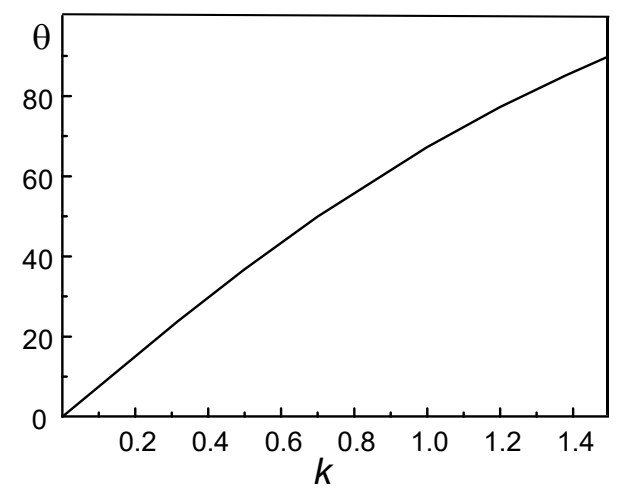

Figure A5. The curves of $\theta$ with respect to $k$.

\section{References}

1. Wong, I.; Yang, H.X. Introducing natural lighting into the enclosed lift lobbies of highrise buildings by remote source lighting system. Appl. Energy 2012, 90, 225-232. [CrossRef]

2. Malet-Damour, B.; Guichard, S.; Bigot, D.; Boyer, H. Study of tubular daylight guide systems in buildings: Experimentation, modelling and validation. Energy Build. 2016, 129, 308-321. [CrossRef]

3. Petržala, J.; Kocifaj, M.; Kómar, L. Accurate tool for express optical efficiency analysis of cylindrical light-tubes with arbitrary aspect ratios. Sol. Energy 2018, 169, 264-269. [CrossRef]

4. Darula, S.; Kittler, R.; Kocifaj, M. Luminous effectiveness of tubular light-guides in tropics. Applied Energy 2010, 87, 3460-3466. [CrossRef]

5. Shuxiao, W.; Jianping, Z.; Lixiong, W. Research on Energy Saving Analysis of Tubular Daylight Devices. Energy Procedia 2015, 78, 1781-1786. [CrossRef]

6. $\quad$ Dugas, J.; Cariou, J.-M.; Martin, L. Optical fibers and solar energy. L'Aeronautique Et L'Astronautique 1982, 92, 57-61. 
7. Nakamura, T.; Case, J.A.; Senior, C.L.; Jack, D.A.; Cuello, J.L. Optical Waveguide System for Solar Energy Utilization in Space. In Proceedings of the SED2002-2002 International Solar Energy Conference, Reno, NV, USA, 15-20 June 2002.

8. Nakamura, T. Optical Waveguide System for Solar Power Applications in Space. In Proceedings of the SPIE Optical Engineering + Applications, San Diego, CA, USA, 20 August 2009.

9. Feuermann, D.; Gordon, J.M. Solar fiber-optic mini-dishes: A new approach to the efficient collection of sunlight. Sol. Energy 2019, 65, 159-170. [CrossRef]

10. Kandilli, C.; Ulgen, K.; Hepbasli, A. Exergetic assessment of transmission concentrated solar energy systems via optical fibres for building applications. Energy Build. 2008, 40, 1505-1512. [CrossRef]

11. Sedki, L.; Maaroufi, M. Design of parabolic solar daylighting systems based on fiber optic wires: A new heat filtering device. Energy Build. 2017, 152, 434-441. [CrossRef]

12. Ullah, I. Fiber-based daylighting system using trough collector for uniform illumination. Sol. Energy 2020, 196, 484-493. [CrossRef]

13. Tao, T.; Hongfei, Z.; Kaiyan, H.; Mayere, A. A new trough solar concentrator and its performance analysis. Sol. Energy 2011, 85, 198-207. [CrossRef]

14. Vu, N.-H.; Shin, S. Cost-effective optical fiber daylighting system using modified compound parabolic concentrators. Sol. Energy 2016, 136, 145-152. [CrossRef]

15. Lei, L.; Juntao, W.; Zhuodong, Y.; Geng, L.; Kai, T.; Jin, Z.; Jifeng, S. An optical fiber daylighting system with large Fresnel lens. Energy Procedia 2018, 152, 342-347. [CrossRef]

16. Vu, N.H.; Pham, T.T.; Shin, S. Modified optical fiber daylighting system with sunlight transportation in free space. Opt. Express 2016, 24, A1528-A1545. [CrossRef]

17. Obianuju, O.N.; Chong, K.-K. High Acceptance Angle Optical Fiber Based Daylighting System Using Two-stage Reflective Non-imaging Dish Concentrator. Energy Procedia 2017, 105, 498-504. [CrossRef]

18. Dawei, L.; Fraser Monteiro, L.; Ribau Teixeira, M.; Co11ares-Pereira, M.; Fraser Monteiro, M.L.; Collares-Pereira, M. Fiber-optic solar energy transmission and concentration. Sol. Energy Mater. Sol. Cells 1998, 54, 323-331.

19. Dawei, L.; Nunes, Y.; Fraser Monteiro, L.; Fraser Monteiro, M.L.; Co11ares-Pereira, M. 200 W solar energy delivery with optical fiber bundles. In Proceedings of the Optical Science, Engineering and Instrumentation 97, San Diego, CA, USA, 3 October 1997.

20. Yuexia, L.; Longyu, X.; Jinyue, Y.; Jinpeng, B. Design of a hybrid fiber optic daylighting and PV solar lighting system. Energy Procedia 2018, 145, 586-591.

21. Schlegel, G.O.; Burkholder, F.W.; Klein, S.A.; Beckman, W.A.; Wood, B.D.; Muhs, J.D. Analysis of a full spectrum hybrid lighting system. Solar Energy 2004, 76, 359-368. [CrossRef]

22. Lv, Y.; Xia, L.; Li, M.; Wang, L.; Su, Y.; Yan, J. Techno-economic evaluation of an optical fiber based hybrid solar lighting system. Energy Convers. Manag. 2020, 225, 113399. [CrossRef]

23. Kaiyan, H.; Hongfei, Z.; Yixin, L.; Ziqian, C. An imaging compounding parabolic concentrator. In Proceedings of the IESE Solar Word Congress, Beijing, China, 18-21 September 2007; pp. 589-592.

24. Kaiyan, H.; Hongfei, Z.; Zhengliang, L.; Tao, T. A novel multiple curved surfaces compound concentrator. Sol. Energy 2011, 85, 523-529. [CrossRef]

25. Kaiyan, H.; Hongfei, Z.; Tao, T.; Dai, J. Design and investigation of a novel concentrator used in solar fiber lamp. Sol. Energy 2009, 83, 2086-2091.

26. Kaiyan, H.; Ziqian, C.; Shuiku, Z.; Yingda, Q.; Haoyue, L.; Junhua, Y.; Bangdi, Z. A solar fiber daylighting system without tracking component. Sol. Energy 2019, 194, 461-470. 